\title{
The Public-Private Wage Gap in Brazil*
}

\author{
Miguel N. Foguel** \\ Indermit Gill*** \\ Rosane Mendonça**** \\ Ricardo Paes de Barros*****
}

Summary: 1. Introduction and motivation; 2. A brief review of the literature; 3. Overall research strategy; 4. Empirical preliminaries; 5 . The overall wage gap; 6 . The heterogeneity within the public sector; 7 . Regional differences and the public-private wage gap; 8 . The role of differences in the characteristics of the labor force; 9 . The sensitivity to the level of geographical aggregation; 10 . The controlled log-wage gap: a disaggregated view; 11 . Conclusion.

Key words: public employment; wage differentials; labor market.

JEL Codes: J45; J31 and J21.

Recent changes in public employment in Brazil generate costs to workers that leave this sector. In this study we investigate the wage loss that leaving public employees may experience if they were absorbed by the private sector. Using microdata from the Pesquisa Nacional por Amostra de Domicílios of 1995, we calculate the gross and controlled wage gaps between the two sectors. The results show that both wage gaps are relatively high, although significantly lower for the second measure. The latter indicates the presence of important differences in the composition of the labor force between the two sectors. In fact, public employees tend to be on average better educated, older and have longer tenure than the workers in the private sector. Also, the study shows that there is a significant heterogeneity within the public sector: the wage gap is higher for federal public employees, decreasing for the state and municipal levels.

As mudanças que vêm ocorrendo no emprego público no Brasil acarretam diversos custos para os trabalhadores que saem desse setor. Neste trabalho investigamos a magnitude da perda salarial que os trabalhadores realocados do setor público para o privado podem experimentar. Utilizando os microdados da Pesquisa Nacional por Amostra de Domicílios (Pnad/IBGE) de 1995, calculamos os hiatos salariais

\footnotetext{
${ }^{*}$ This paper was received in Dec. 1999 and approved in July 2000. The authors would like to thank their research team at the Institute of Applied Economic Research (Ipea), in particular to Daniela Costa and Phillippe Leite.

** Researcher of the Social Studies Division at Ipea.

*** Economist of the Brazil Country Management Unit at the World Bank.

**** Researcher of the Social Studies Division at Ipea and assistant professor at Fluminense Federal University (UFF).

***** Director of the Social Studies Division at Ipea.
}

RBE Rio de Janeiro 54(4):433-472 OUT./DEZ. 2000 
bruto e controlado entre esses setores. Os resultados obtidos mostram que esses hiatos salariais são relativamente altos, embora significativamente menores quando utilizamos a segunda medida. Essa última constatação indica a existência de diferenças na composição da força de trabalho entre os dois setores. De fato, os trabalhadores empregados no setor público tendem a ser em média mais escolarizados, mais velhos e possuírem maior tempo de experiência no trabalho do que os trabalhadores empregados no setor privado. Outra constatação importante é a presença de uma significativa heterogeneidade dentro do setor público: o hiato salarial é maior para os empregados na esfera federal, decrescendo para os níveis estadual e municipal.

\section{Introduction and Motivation}

An ongoing privatization program, a chronic public deficit and a perception of great inefficiencies in the public sector are forces that are or will eventually, in the near future, lead to reductions in employment in the public sector, in absolute terms. As a result of this expected shrinking of the public sector, a number of public employees will eventually have to be absorbed by the private sector. For the workers in the public sector, the cost of this reallocation will depend on the quantity and quality of their opportunities in the private sector. What are the chances of workers in the public sector of quickly finding new jobs in the private sector? By how much are their wages expected to decline as a result of this reallocation?

In this study we investigate one of the most important dimensions of the cost associated to the reallocation of workers from the public to the private sector: the wage loss this reallocation is likely to entail. This wage loss will be referred in this study as the wage gap between the public and private sectors.

\section{A Brief Review of the Literature}

The literature on Brazilian labor market has paid very little attention to the wage gap between the public and private sectors. ${ }^{1}$ As a consequence, just a few estimates are available. The major studies are Macedo (1985a) and Saldanha, Maia, and Camargo (1988). ${ }^{2}$ Both studies compare the wages in the

\footnotetext{
${ }^{1}$ Most of the literature on public employment in Brazil has focus on the employment dimension. As a matter of fact, the literature on the level and composition of public employment is relatively rich. See, for instance, Barros 6 Ramos (1991) and Maia 6 Saldanha (1988).

${ }^{2}$ See also Macedo (1985b) for a short version of Macedo (1985a).
} 
federal public sector to the wages in the formal private sector using information from the Relação Anual de Informações Sociais (Rais, Yearly Social Data Register). As a consequence, these studies provide no guide about the wage gap between the private sector, on the one hand, and the state and municipal public sectors, on the other. Moreover, they also provide no evidence on the wage gap between the public sector and the informal private sector.

Macedo's study concentrates its attention on the wage gap between public and private enterprises. He studies the public-private wage gap for 10 industries. He found that within most of these 10 industries, public enterprises pay, on average, much higher wages than their private counterparts (Macedo, 1985a:39). However, as he emphasizes, there are large differences in the characteristics of workers in the public and private sectors that can explain at least partially these wage differences. As a second step, he estimates the wage gap controlling for these differences in characteristics. The estimated controlled wage gap continues to indicate that public enterprises pay on average much higher wages to workers with identical observed characteristics and in the same occupation than do private enterprises of similar size in the same industry. Macedo's estimated wage gap among workers with identical observed characteristics in the same occupation and industry varies between 70 and $250 \%$ of the average wage in the private sector depending on the methodology used (Macedo, 1985a:59-62). It is worth mentioning that these estimates refer to a very specific occupation and for a pair of enterprises in a very specific industry. Hence, on the one hand, they serve to indicate that great wage differentials persist even when one compares very similar workers in the same occupation and enterprises of similar size in the same industry. On the other hand, the differential is valid only for the specific occupation and industry investigated. It may be very different in other occupations and industries.

The study by Saldanha, Maia, and Camargo (1988) contrasts the wages and other monetary benefits between several segments of the federal public sector with the wages in the formal private sector. This study finds very large wage differences between the public and the formal private sectors. The estimated public-private wage is equivalent to $52 \%$ of the average wage in the formal private sectors. Moreover, the study shows that the income differences are even greater, $85 \%$, when other non-wage monetary benefits are included (bonus, overtime, quinquennial, productivity). The study mentions that part 
of the large wage gap between the public and private sectors could be due to sectoral differences in the characteristics of the labor force, but no systematic attempt is made to control for these differences as in the regressions performed by Macedo (1985a and 1985b). One of the main emphasis of the Saldanha, Maia, and Camargo study is to document the enormous degree of wage heterogeneity between segments of the public sector, with wages and other monetary benefits in the federal administration being much smaller than in public enterprises.

\section{Overall Research Strategy}

In this study we seek to extend and update the analysis initiated by Macedo (1985a). We use a similar methodology, but a different source of information: Pesquisa Nacional por Amostra de Domicílios (National Research by Domicile Sampling, Pnad), 1995. We extend his analysis by considering all segments of the public sector (public enterprises and direct administration) and all levels of affiliation (federal, state and municipal). Moreover, we compare the wages in the public sector not only to the average wage in the formal private sector but also to the average wage for the overall private sector.

To investigate the public-private wage gap we proceed, as Macedo (1985a) did, in two steps. We begin by estimating the overall wage gap between the private and public sectors for the entire Brazilian labor market (section 5). We then turn, still in the first step, to examine the heterogeneity within the public sector (section 6). We estimate the wage gap between segments of the public sector and the overall private sector.

Although these estimates of the wage gap represent an important starting point, they have serious limitations as a measure of the actual difference in wage attractiveness between the public and private sectors, since they do not necessarily represent the actual difference in pay between equally productive workers in the public and private sectors. In other words, they do not necessarily indicate what would be the wage loss of a worker switching from the public to the private sector.

In general, the overall wage gap between sectors captures both differences in pay between equally productive workers in the two sectors and differences in characteristics (differences in qualifications, in particular) of the labor force 
employed in the two sectors. Accordingly, on the one hand, wages tend to be higher in the public sector simply because its labor force is older, better educated and non-whites are underrepresented. On the other hand, wages in the public sector tend to be lower due to the concentration of public employment in the less-developed Northeast and because women tend to be overrepresented in the public sector.

To surpass these difficulties, at least partially, in a second step we estimate the wage gap between workers in the public and private sectors with similar observable characteristics. The goal is to approximate the wage gap between equally productive workers in the two sectors.

Section 7 investigates the impact of differences in the spatial location of the public and private jobs on the overall wage gap between the sectors. More specifically, we investigate to which extent the overrepresentation of public employment in the Brazilian Northeast tends to make overall measures of the wage gap between the public and private sectors an underestimate of the actual gap faced by local labor markets. Moreover, since the process of purging the wage gap from sectoral differences in the characteristics of the labor force will require us to concentrate our attention to a few metropolitan areas, this section will also serve to indicate to which extent the wage gap in these areas are typical of what it is observed throughout Brazil.

In section 8 we estimate the wage gap between workers with identical observed characteristics in the public and private sectors. We refer to these estimates as the controlled wage gap. To make this analysis empirically feasible we limit the scope to the six major Brazilian metropolitan areas and the Federal District of Brasília.

Since the wage gap between the public and private sectors are likely to differ among workers with different characteristics, in section 9 we briefly investigate how the wage gap varies with workers' observed characteristics. Finally, in section 10, we present estimates for the controlled wage gap between segments of the public sector and the overall private sector. However, before we actually proceed to report and analyze the estimates for the public-private wage gap, we present in the following section a description of the data base and the empirical concepts and definitions used throughout the study. In the appendix we present a methodological discussion on how to measure wage gaps. 


\section{Empirical Preliminaries}

The empirical analysis conducted in this section is entirely based on the 1995 version of the Pnad. Consequently, all wage comparisons presented in this study reflect the conditions of the Brazilian labor market prevailing in September 1995.

The basic universe of analysis is the occupied labor force at least 10 years old with positive labor income. ${ }^{3}$ In this study we classify a person as occupied when he or she hold a job during at least part of the reference week of the survey.

Throughout this study we use two measures of labor income. The first is the gross monthly income normally received by a worker in his/her main job. ${ }^{4}$ The second seeks to approximate a measure for wage by standardizing the labor income for the number of hours worked. It is defined as the monthly income divided by the number of hours usually worked per week in the main job and multiplied by a standard workweek of 40 hours.

Since the average number of hours worked by public employees tends to be significantly smaller than the corresponding average for workers in the private sector, it does make a significant difference for the level of the wage gap between these sectors whether a standardization for hours of work is conducted or not. By standardizing for hours worked, we implicitly assume that the average and marginal wages are identical. As a consequence, we also exclude from the analysis those working less than 20 hours per week, since they are likely to violate this assumption.

In this study we consider the public sector as a whole, as well as a disaggregation of it into eight segments. This segmentation of the public sector is based on a combination of the type of labor contract (public servant and employees with and without a formal labor contract) and the level of the public affiliation (federal, state, and municipal), with the military personnel being treated separately. Table 1 presents a summary of the dissagregation used in this study, as well as the percentage of the labor force in each category. As this table reveals, we do not treat separately the employees without a formal labor contract according to their level of affiliation. This table reveals that

\footnotetext{
${ }^{3}$ We also exclude the workers working less than 20 hours per week.

${ }^{4}$ It includes both cash payments and the monetary equivalent to payments in goods.
} 
public sector employment as a whole responded in 1995 for $13,4 \%$ of total employment in Brazil. State public employment represents the largest share in public employment, followed by municipal and federal public employment, respectively.

Table 1

Total employment by category in Brazil (1995)

\begin{tabular}{lcr}
\hline Sector & $\begin{array}{c}\text { Total employment } \\
\text { (millions) }\end{array}$ & $\begin{array}{c}\text { Shares } \\
(\%)\end{array}$ \\
\hline Public sector & 7.8 & 13.4 \\
$\quad$ Public servants - federal & 0.6 & 1.1 \\
Non-public servants with a signed & 0.4 & 0.7 \\
$\quad$ working card - federal & 2.4 & 4.1 \\
Public servants - state & & \\
Non-public servants with a signed & 0.7 & 1.2 \\
$\quad$ working card - state & 1.3 & 2.2 \\
Public servants - municipal & & \\
Non-public servants with a signed & 1.0 & 1.8 \\
$\quad$ working card - municipal & & \\
Non-public servants without a signed & 1.0 & 1.8 \\
$\quad$ working card - federal, state and municipal & 0.3 & 0.5 \\
$\quad$ Military personnel & 50.7 & 86.6 \\
Private sector & 18.3 & 31.3 \\
$\quad$ Workers with a signed working card & 14.4 & 24.6 \\
$\quad$ Workers without a signed working card & 15.3 & 26.2 \\
Self-employed & 2.7 & 4.5 \\
$\quad$ Employers & 58.5 & 100.0 \\
Total & & \\
\hline
\end{tabular}

Source: Based on information of Pnad/1995 (IBGE, 1996).

In addition to these concepts and variables, we also use in the empirical analysis indicators for gender, race and geographical location, and measures for age, education and tenure. Out of these variables, two deserve further comments: race and education. In the case of race it is important to emphasize that we cluster all non-white categories available (mulatos, blacks and indigenous). To measure education, we use the number of completed years of schooling. We measure tenure by how long (in years) workers have been in their current job.

Table 2 presents the average value for some of these workers' characteristics by sector. This table reveals that workers in the public sector are better 
educated and older. Moreover, this table reveals that while women are overrepresented in the public sector, and non-whites are underrepresented.

Table 2

Shares in employment by characteristic in Brazil (1995)

\begin{tabular}{lcc}
\hline Characteristic & Public sector & Private sector \\
\hline Sex & & \\
Male & 42.6 & 67.7 \\
Female & 57.4 & 32.3 \\
Race & 62.1 & 58.0 \\
White & 37.9 & 42.0 \\
Non-white & & \\
Age & 13.3 & 26.1 \\
10-24 years & 30.8 & 27.6 \\
25-34 years & 30.5 & 23.1 \\
35-44 years & 18.2 & 13.8 \\
45-54 years & 7.2 & 9.4 \\
More than 55 years & & \\
Education & 4.1 & 13.7 \\
0 year & 17.7 & 37.0 \\
1-4 years & 15.2 & 25.1 \\
5-8 years & 32.4 & 16.6 \\
9-11 years & 30.5 & 7.5 \\
More than 12 years & & \\
\hline
\end{tabular}

Source: Based on information of Pnad/1995 (IBGE, 1996).

\section{The Overall Wage Gap}

\subsection{Estimates for the wage gap}

Table 3 presents estimates for the wage gap between the public and private sectors in Brazil. Estimates for all four alternative measures for the wage gap are presented in the table. ${ }^{5}$ In all cases, the evidence clearly reveals a large wage gap, indicating that wages tend to be much higher in the public than in the private sector. More specifically, this table reveals that the public-private wage gap is equivalent to $38 \%$ (61\%) of the average wage in the public (private) sector. These estimates refer to the gap in labor income standardized for the number of hours worked.

\footnotetext{
${ }^{5}$ See the appendix for a description of these measures.
} 
Table 3

Wage gap betwen the public and private sectors in Brazil (1995)

\begin{tabular}{|c|c|c|c|c|}
\hline & \multicolumn{2}{|c|}{ Public-overall private } & \multicolumn{2}{|c|}{ Public-formal private } \\
\hline & Standardized & $\begin{array}{c}\text { Non- } \\
\text { standardized }\end{array}$ & Standardized & $\begin{array}{c}\text { Non- } \\
\text { standardized }\end{array}$ \\
\hline $\begin{array}{l}\text { Relative wage gap }-\mathrm{G}_{1 a} \\
\text { (baseline: wage in public sector) }\end{array}$ & 0.38 & 0.31 & 0.34 & 0.24 \\
\hline $\begin{array}{l}\text { Relative wage gap }-\mathrm{G}_{1 b} \\
\text { (baseline: wage in private sector) }\end{array}$ & 0.61 & 0.45 & 0.53 & 0.32 \\
\hline Gap in log-average-wages $-\mathrm{G}_{2}$ & 0.47 & 0.37 & 0.42 & 0.28 \\
\hline Gap in average log-wage $-\mathrm{G}_{3}$ & 0.58 & 0.43 & 0.48 & 0.33 \\
\hline
\end{tabular}

Source: Based on information of Pnad/1995 (IBGE, 1996).

This table also presents estimates for the gap in labor income nonstandardized for the number of hours worked. These estimates reveal that the gap in non-standardized labor income is smaller - 31\% (45\%) of average income in the public (private) sector -, corroborating the fact that employees in the public sector work fewer hours per week than workers in the private sector. As a result, the gap in standardized wages tends to be between 0.23 and 0.36 greater than the corresponding gap in non-standardized wages, depending on how we measure the gap. Throughout this study we will concentrate our analysis on the gap in standardized wages. ${ }^{6}$

Since the private sector in Brazil includes a large fraction of self-employed and employees with informal labor contracts, it is important at this point to clarify to what extent this large public-private wage gap is just a feature of a large degree of informality in the private sector. To check for this possibility, table 3 also presents estimates of the wage gap between employees in the public sector and in the private formal sector. ${ }^{7}$ The table reveals that this wage gap is only slightly smaller than the one between the public sector and the overall private sector. More specifically, the wage gap between the public sector and the private formal sector as a percentage of the public sector average wage is no more than 10 percentage points smaller. In sum, the wage advantage of the public sector is not explained, by any significant margin, by a large informal sector.

\footnotetext{
${ }^{6}$ The corresponding gaps in non-standardized income are presented in Barros et alii (1997).

${ }^{7}$ Employees in the private formal sector are all those in the private sector who have a formal labor contract.
} 


\subsection{Interpreting the wage gap}

At this stage of the analysis, it is very difficult to interpret these very large wage gaps, since, as emphasized by Macedo (1985a), they may be just reflecting sectoral differences in the composition of the labor force. The labor force in the public sector tends to be better educated and to have greater labor market experience. It also tends to have a higher percentage of women and to be concentrated in the Northeast. Thus, the natural next step is to estimate the wage gap between workers in the public and private sectors with identical observed characteristics. Nevertheless, before we proceed in this direction, we dedicate the next section to the analysis of the degree of wage heterogeneity within the public sector.

\section{The Heterogeneity within the Public Sector}

To investigate the heterogeneity within the public sector, we use the disaggregation of the sector based on information on the type of labor contract and on the level of government affiliation presented in table 1 and discussed above, in section 5. Table 4 presents estimates for the gap in wages between each of these segments of the public sector and the overall private sector. The results indicate an enormous level of heterogeneity within the public sector, with the average wage gap being much higher for certain segments of the public sector than for others.

More specifically, table 4 reveals that wages are particularly high among federal public servants and employees in federal enterprises. ${ }^{8}$ In both cases the wage gap is greater than $150 \%$ of the average wage in the private sector. The military personnel, state public servants and employees of state enterprises make a second tier. The average wage gap between this group and the average for the private sector is between 50 and $100 \%$ of the average wage in the private sector. The third group is composed by municipal public servants, employees of municipal enterprises and non-public servants without a signed working card for the three levels of government. The average wage of workers in these groups is below the average for the private sector, with the wages of employees in municipal enterprises being particularly low.

\footnotetext{
${ }^{8}$ For simplicity, we identify workers in the public sector with signed working card with employees in public enterprises.
} 
Overall, table 4 reveals a very large degree of heterogeneity in wages among segments of the public sector. For instance, the wage gap between federal public servants and the private sector, as a percentage of the average wage paid by the private sector, is more than 230 percentage points higher than the corresponding wage gap relative to municipal public servants. Hence, any overall estimates for the public-private wage gap are necessarily an average of a very heterogeneous set of wage gaps, and so are very sensible to the weights used to compute the average. In sum, considerable caution should be taken when interpreting overall estimates of the public-private wage gap.

\section{Regional Differences and the Public-Private Wage Gap}

In the previous two sections we have considered the magnitude of the overall wage gap between the public and private sectors. This overall gap, however, captures both intrinsic sectoral differences in wages and sectoral differences in the characteristics of workers. To get a better idea of the actual wage advantage of the public sector it is necessary to compare the wage of similar workers in the two sectors. We pursue this goal by a series of steps. We begin in this section by considering the role of spatial differences in the distribution of public and private employment.

More specifically, in this section we investigate three inter-related topics. First, we investigate whether public employment is in fact unevenly distributed across states. In particular, we investigate whether public employment is overrepresented in states with below average income. Secondly, we investigate how the uneven distribution of public employment across states impacts on the overall level of the wage gap between the public and private sectors, obtaining, in particular, the average within-state public-private wage gap. Finally, we investigate how the within-state public-private wage gap varies across states.

To address these three questions, we have to consider two types of information that are presented in table 5 :

a) the spatial distribution of the labor force in the public and private sectors across states;

b) the average wage and log-wage in the public and private sectors by state. 


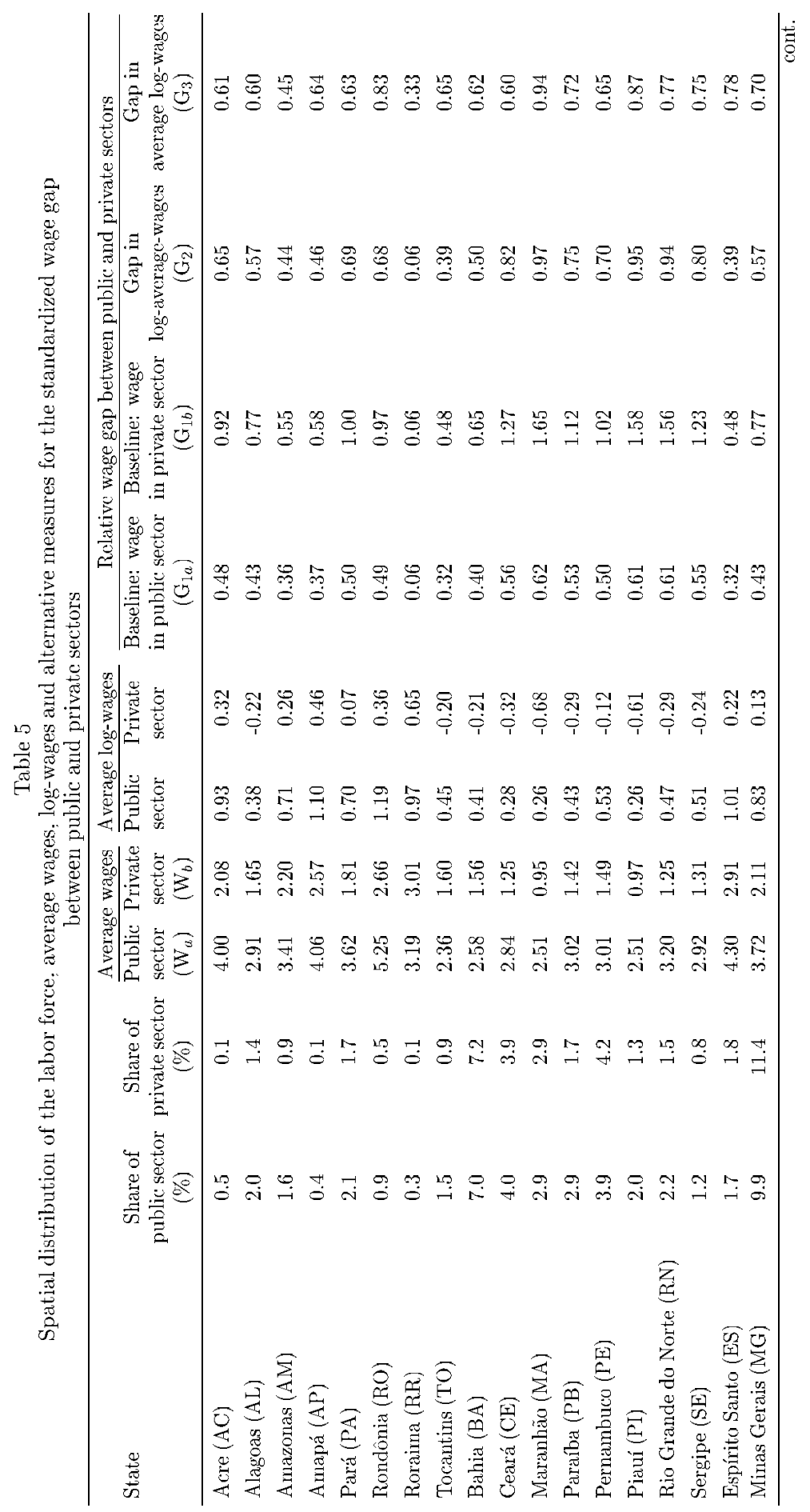




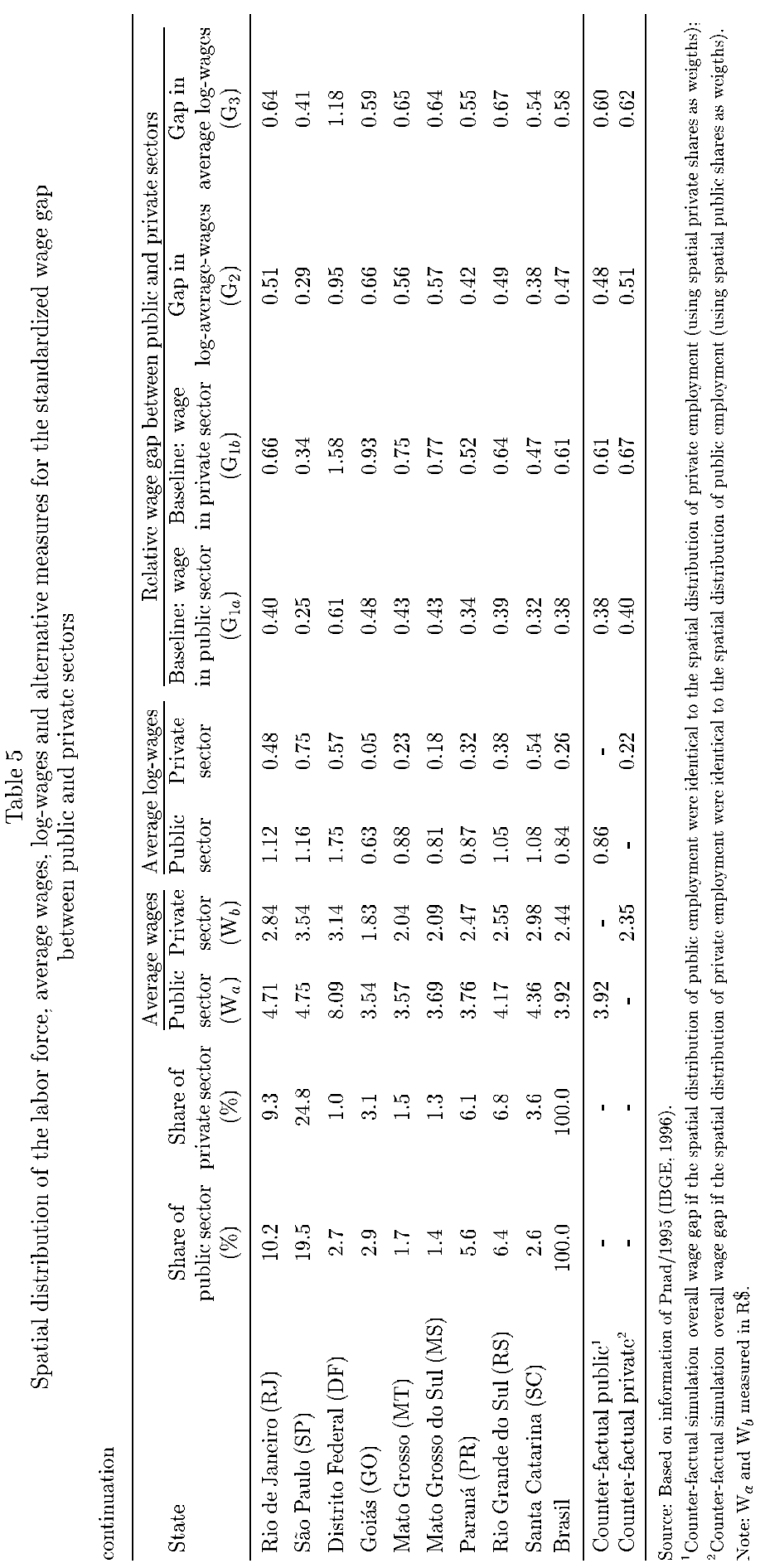




\subsection{Public-private differences in spatial distribution}

As far as differences in the spatial distribution of the labor force are concerned, table 5 reveals that public employment tends to be overrepresented both in the very poor (Northeastern states) and in the very rich areas (Federal District and the state of Rio de Janeiro). Overall, however, the employment in the public sector tends to be slightly overrepresented in the poorest areas.

To graphically illustrate this spatial disadvantage of public employment, we built figure 1, where we first ranked states based on their average log-wage in the private sector, then we computed the cumulative proportion of employment in the poorest states for the public and private sectors separately. This figure reveals that the cumulative distribution for the employment in the public sector is most of the time above the corresponding distribution for the private sector; the exception is the very upper tail of the distribution (high income states). For instance, figure 1 reveals that while $49 \%$ of public employment are in states with wages below average, only $46 \%$ of private employment are located in such states. This fact is a confirmation that public employment is slightly overrepresented in the poorest states. The area between these two cumulative distributions can be used as a measure of the magnitude of this overrepresentation (i.e., the locational disadvantage of public employment). The area is 0.02 . It means that the average wage in the private sector would be 0.02 smaller if the spatial distribution of workers in the private sector were changed to equal the current spatial distribution of workers in the public sector, revealing that public employment indeed exhibits a small degree of locational disadvantage.

\subsection{The average within state public-private wage gap}

One of the consequences of employment in the public sector being overrepresented in the poorest states is that estimates of the overall wage gap tends to underestimate the wage gap within states. To evaluate the average wage gap within state, we estimate what would be the overall wage gap if the spatial distribution of private employment were changed to become identical to the spatial distribution of public employment (i.e., if the locational disadvantage of public employment were eliminated). The results indicate that the gap in average log-wage would increase from 0.44 to 0.46 . The difference between these two log-wage gaps, 0.02 , is both a measure of the locational disadvantage of public employment and a measure of the degree the overall wage gap underestimates the wage gap within states. It can be shown that it equals the area between the two curves in figure 1. 


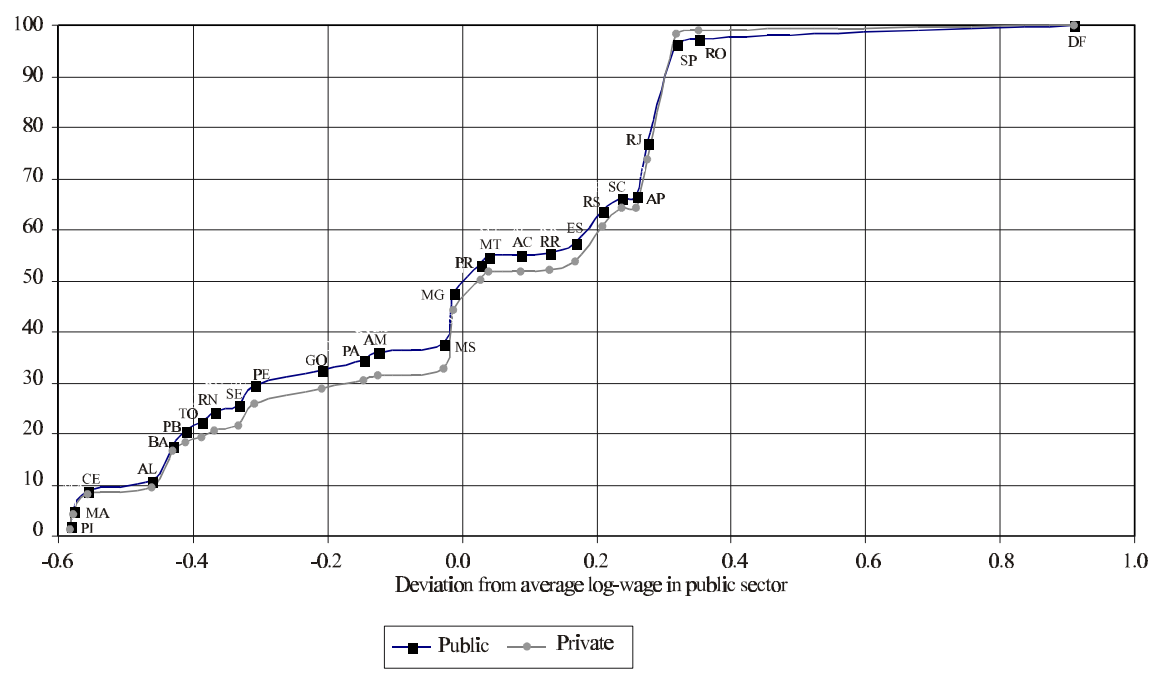

\subsection{Regional variations in the average within state public-private wage gap}

Finally, the evidence in table 5 also permits to investigate how the wage gap between the public and private sectors varies across states. The evidence on this question is presented in figure 2. This figure clearly reveals that the average log-wage gap between the public and private sectors is much higher in the Federal District than in any of the 26 Brazilian states. This figure also shows that the average log-wage gap tends to be higher in the Northeastearn States, but not as high as in the Federal District. On the other extreme, the average log-wage gap tends to be lower in the more developed states in the South and Southeast of Brazil, particularly in São Paulo, Paraná and Santa Catarina. But it is also very low in a few poor states like Ceará and Alagoas.

At this stage of the analysis, it is still very difficult to interpret these very high levels for the log-wage gap within states, and the sharp regional variations. On the one hand, these very high levels for the wage gap may be just reflecting differences in the characteristics of the labor force employed in the public and private sectors. On the other hand, the large regional differences may just reflect regional differences in the internal composition of the public sectors or regional differences in the magnitude of the sectoral 
differences in the composition of the labor force. Accordingly, in the next section we proceed to the analysis by seeking to further isolate the fraction of the wage gap that is just due to sectoral differences in the composition of the labor force.

Figure 2

Average log-wage gap between the public and private sectors (G3)

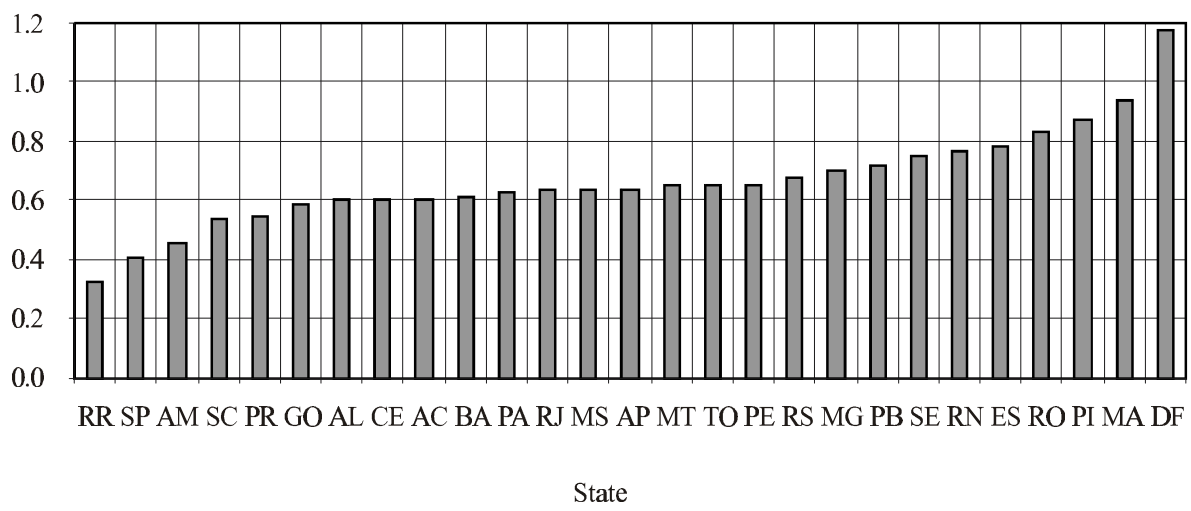

Since in the subsequent analysis we restrain ourselves to the labor market of the major six Brazilian metropolitan areas and the Federal District, we finish this section comparing the public-private wage gap for these areas with those for the entire country and for their respective states. Table 6 presents estimates for the public-private wage gap for these spatial disaggregations. This table reveals that in the poorest states (the Northeastern states and Minas Gerais) the wage gap tends to be considerably higher for the metropolitan areas than for the states as a whole. In Rio Grande do Sul the metropolitan gap is also greater than the gap for the entire state. São Paulo and Rio de Janeiro are the only states where the wage gap for the metropolitan area is smaller than the corresponding gap for the entire states.

\section{The Role of Differences in the Characteristics of the Labor Force}

In this section we investigate the contribution of differences in the characteristics of the labor force between the public and private sectors to the wage gap within the metropolitan area. The fundamental question is: what fraction of the wage gap between the two sectors is just due to sectoral differences in the characteristics of the labor force employed in the two sectors, and what fraction is due to real sectoral differences in pay? 


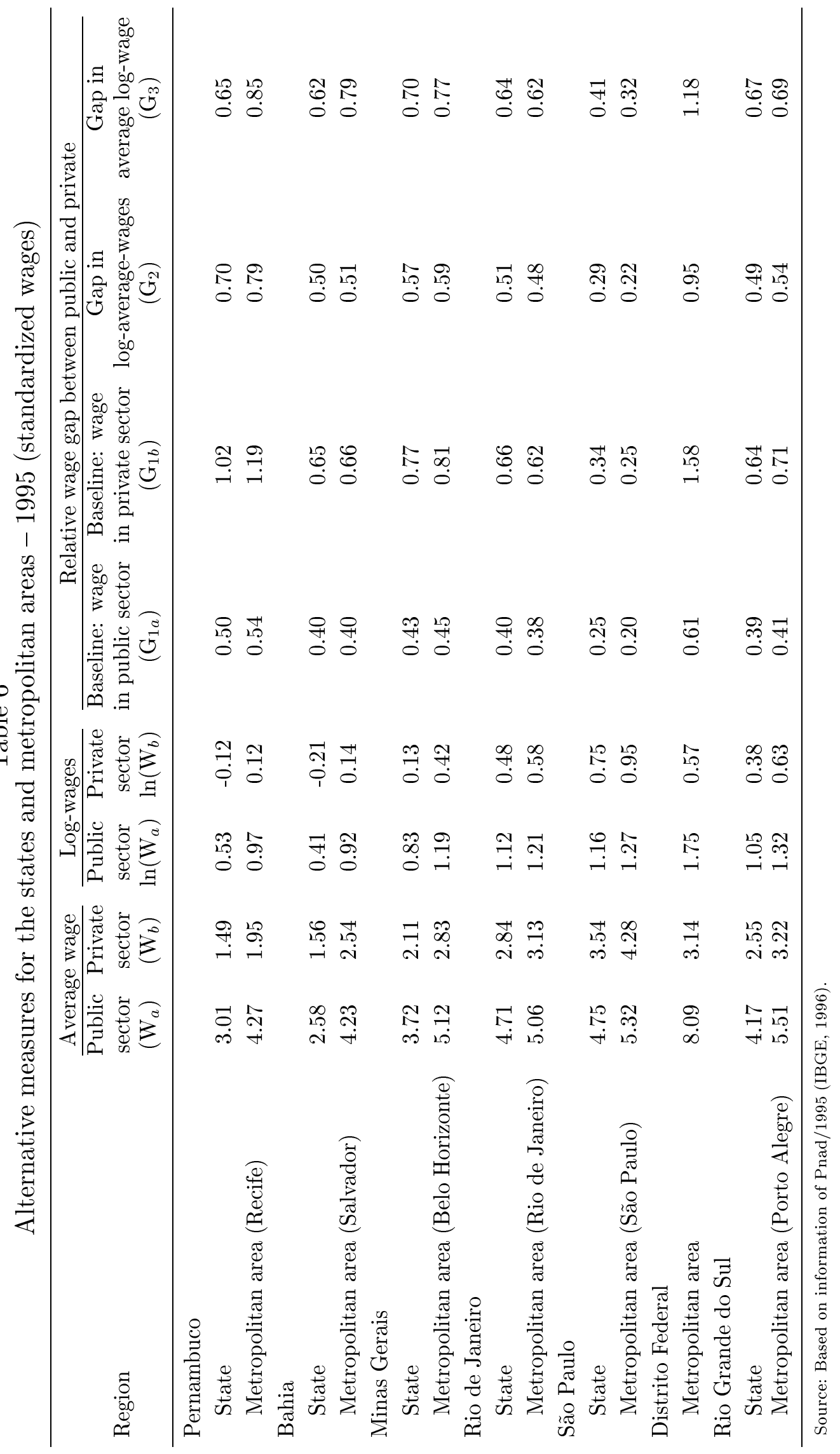


To investigate this question we restrict our attention to the labor markets of the major six Brazilian metropolitan areas and the Federal District. The restriction of the analysis to these seven well-defined local labor markets is an attempt to simplify the control for spatial differences among local markets. This restriction, however, also has some important disadvantages. The major one is the fact that the nature of public employment in large metropolitan areas is likely to be very distinct from its nature in smaller urban areas. The contribution of federal and state employment is likely to be greater. Moreover, municipal jobs in metropolitan areas and in capital cities, in particular, are bounded to be atypical. They are probably of considerable better quality than those of smaller municipalities in non-metropolitan areas. As a consequence, the wage gap estimated for these areas is likely to overestimate the gap for the entire urban labor market in the state. Table 6 already presented some evidence in this direction. To verify the robustness of the results presented in this section, in the subsequent section we briefly replicate the analysis, using the corresponding states instead of their metropolitan areas.

\subsection{Methodology}

The basic methodology consists of estimating the wage gap between workers with identical observed characteristics in the public and private sectors. This wage gap, which will be referred as the controlled wage gap, is taken as an estimate of the wage advantage faced by workers in the public sector. The difference between this gap and the overall gross wage gap is a measure of the contribution of sectoral differences in the composition of labor force to the overall (gross) wage gap.

At this point it is worth mentioning that the controlled wage gap is not necessarily a consistent estimator of the actual wage advantage faced by workers in the public sector. To obtain a consistent estimator of the actual wage advantage, it would be necessary to control for all sectoral differences in workers' characteristics. To control just for a limited set of observed characteristics, as it is done to obtain the controlled wage gap, may not be enough. Furthermore, and even more disturbing, there is no theoretical reason to believe that controlling for a subset of characteristics (as we do to obtain the controlled wage gap) we would get any closer to the actual wage advantage of the public sector than we would get if no controls were introduced. In fact, it is possible to find situations where the introduction of partial controls will move 
the estimates away from the true wage advantage (Griliches, 1977). In sum, there is no theoretical reason to believe that the controlled wage gap is an improvement upon the gross wage gap.

In this section we investigate the wage gap for each metropolitan area separately. The basic set of observed characteristics used as controls comprises gender, race, schooling, and age. We also work with an augmented version of this set that includes tenure on the job. Since, to a considerable extent, the longer average tenure of public employees is not a result of any differential merit between employees in the public and private sectors, but one of the major advantages of jobs in the public sector, it is unclear whether or not we should control for this characteristic. To compromise, we present all results including and excluding this characteristic from the set of controls.

The methodology used to compare the wage of observably identical workers in the public and private sectors consists of three steps. In the first, we regress the log-wages of workers on their characteristics and on an indicator of whether they are in the public or in the private sector. In the second step, based on the results of this regression, we compute what would be the average wage of public employees if they were in the private sector, given their personal characteristics. Finally, we obtain the wage gap between workers with identical observed skills as the difference between the actual average log-wage in the public sector and the average log-wage they would receive if they were in the private sector, as estimated in the second step.

We implement this procedure using two alternative specifications for the log-wage regressions. To describe the specification of these regressions, we concentrate the attention on the regressions that include tenure; the regressions without tenure are obtained simply by removing tenure from the specification.

We begin establishing a notation. Thus, let w denote the log-wage, and $h$ the regression function of log-wages on gender $(g)$, race $(r)$, schooling $(e)$, age $(a)$, tenure $(t)$, and an indicator for the public sector $(p)$, i.e.,

$$
E[w / g, r, e, a, t, p]=h(g, r, e, a, t, p)
$$

Given this notation, the specification of the regressions can be seen as a series of hypothesis about the functional form of $h$. Our basic assumption is that the regression function is separable on gender, race, schooling, age, and tenure, but not necessary on the indicator for the public sector, i.e.,

$$
h(g, r, e, a, t, p)=f_{1}(g, p)+f_{2}(r, p)+f_{3}(e, p)+f_{4}(a, p)+f_{5}(t, p)
$$


It is central to certain segments of the analysis on this study to allow for the regression function to be non-separable on $p$ (the indicator for the public sector). This non-separability is a necessary condition for the wage advantage of workers in the public sector to vary with their characteristics. If the regression function were separable in $p$, the wage advantage would be identical for all types of workers.

To further simplify the empirical analysis, we assume that the dependencies on schooling and tenure are linear and the dependency on age is quadratic, i.e., we assume that

$$
\begin{aligned}
& f_{3}(e, p)=a_{3}(p) \cdot e \\
& f_{5}(t, p)=a_{5}(p) \cdot t
\end{aligned}
$$

and that

$$
f_{4}(a, p)=a_{4}(p) \cdot a+b_{4}(p) \cdot a^{2}
$$

Moreover, we can, without any loss of generality, write the functions on gender and race also as linear, since gender and race are dichotomous variables, i.e., we can, without any loss of generality, write:

$$
f_{1}(g, p)=a_{1}(p) \cdot g
$$

and

$$
f_{2}(r, p)=a_{2}(p) \cdot r
$$

Collecting all these results, we can express the log-wage regression function as:

$h(g, r, e, a, t, p)=a_{0}(p)+a_{1}(p) \cdot g+a_{2}(p) \cdot r+a_{3}(p) \cdot e+a_{4}(p) \cdot a+b_{4}(p) \cdot a^{2}+a_{5}(p) \cdot t$

This expression is our first specification for the regression function. It will be referred as the general model. We also estimate and analyze a simplified version of this model, which will be referred as the basic model. To obtain the basic model we further assume the regression to be separable on $p$, the indicator for the public sector. This hypothesis is equivalent to assume that the impact of all personal characteristics on the level of wages is the same in the public and private sectors. That is, if we assume that all coefficients except the intercept are common to both sectors, the regression functions in the two sectors are parallel. In this case the regression model becomes:

$$
h(g, r, e, a, t, p)=a_{0}(p)+a_{1} \cdot g+a_{2} \cdot r+a_{3} \cdot e+a_{4} \cdot a+b_{4} \cdot a^{2}+a_{5} \cdot t
$$


Since $p$ is also a dichotomous variable, without any loss of generality we can express the function $a_{0}$ as a linear function, i.e.,

$$
h(g, r, e, a, t, p)=\alpha+a_{0} \cdot p+a_{1} \cdot g+a_{2} \cdot r+a_{3} \cdot e+a_{4} \cdot a+b_{4} \cdot a^{2}+a_{5} \cdot t
$$

The general model is estimated running regressions of log-wages on gender, race, schooling, age and tenure for the public and private sectors separately. As already mentioned, this specification has the advantage of permitting to evaluate how the wage gap between the public and private sectors varies with workers' characteristics. The basic model assumes that the wage gap is the same for all types of workers. It is estimated by running a single regression of log-wages on gender, race, schooling, age, tenure, and an indicator for public employment in a sample pooling together workers in the public and private sectors.

In the case of the general model, the average log-wage in the public sector $(p=1)$ is given by:

$$
\begin{aligned}
a_{0}(1) & +a_{1}(1) \cdot \mu(g / 1)+a_{2}(1) \cdot \mu(r / 1)+a_{3}(1) \cdot \mu(e / 1)+a_{4}(1) \cdot \mu(a / 1)+ \\
& +b_{4}(1) \cdot \mu\left(a^{2} / 1\right)+a_{5}(1) \cdot \mu(t / 1)
\end{aligned}
$$

where, $\mu(x / 1)$ denotes the average of the characteristic $x$ in the public sector. Based on the same model, the average log-wage that would prevail in the private sector $(p=0)$ if the labor force in the sector had the same characteristics as those of the public sector is given by:

$$
\begin{aligned}
a_{0}(0) & +a_{1}(0) \cdot \mu(g / 1)+a_{2}(0) \cdot \mu(r / 1)+a_{3}(0) \cdot \mu(e / 1)+a_{4}(0) \cdot \mu(a / 1)+ \\
& +b_{4}(0) \cdot \mu\left(a^{2} / 1\right)+a_{5}(0) \cdot \mu(t / 1)
\end{aligned}
$$

Therefore, the estimate of the average log-wage gap between workers with identical observed characteristics, the controlled wage gap, is given by:

$$
\begin{aligned}
\Delta a_{0} & +\Delta a_{1} \cdot \mu(g / 1)+\Delta a_{2} \cdot \mu(r / 1)+\Delta a_{3} \cdot \mu(e / 1)+\Delta a_{4} \cdot \mu(a / 1)+ \\
& +\Delta b_{4} \cdot \mu\left(a^{2} / 1\right)+\Delta a_{5} \cdot \mu(t / 1)
\end{aligned}
$$

where

$$
\Delta a_{i}=a_{i}(1)-a_{i}(0)
$$

In the case of the basic model, the average log-wage in the public sector is given by:

$\alpha+a_{0}+a_{1} \cdot \mu(g / 1)+a_{2} \cdot \mu(r / 1)+a_{3} \cdot \mu(e / 1)+a_{4} \cdot \mu(a / 1)+b_{4} \cdot \mu\left(a^{2} / 1\right)+a_{5} \cdot \mu(t / 1)$ 
And the average log-wage that would prevail in the private sector if the labor force in the sector had the same characteristics as those of the public sector labor force is given by:

$\alpha+a_{1} \cdot \mu(g / 1)+a_{2} \cdot \mu(r / 1)+a_{3} \cdot \mu(e / 1)+a_{4} \cdot \mu(a / 1)+b_{4} \cdot \mu\left(a^{2} / 1\right)+a_{5} \cdot \mu(t / 1)$

As a consequence, the estimate of the log-wage gap between workers with identical observed characteristics, the controlled wage gap, is given simply by $a_{0}$.

\subsection{Empirical results}

\section{The controlled wage gap}

Table 7 presents, for each metropolitan area, estimates of the log-wage gap between workers with identical observed characteristics, i.e., the controlled wage gap for both the general and the basic models. It also shows the corresponding gross wage gap for comparison. The difference between the gross and the controlled wage gaps is a measure of the contribution of sectoral differences in the characteristics of the worker to the wage gap.

Table 5 reveals that the controlled wage gap is positive and significant in all metropolitan areas except São Paulo. The estimated gap is between 0.1 and 0.2 in four out of the seven metropolitan areas. The exceptions are, on the one hand, the Federal District and Recife, where the gap is particularly large and, on the other hand, São Paulo, where the gap is negative. These results indicate, in particular, that the controlled wage gap varies considerably across metropolitan areas. All these results are very similar whether we use the basic or the general model, but are sensitive to the inclusion of controls for tenure. The controlled wage gap tends to be 0.1 smaller when controls for tenure are included (table 5).

Although positive and sizeable in all metropolitan areas except São Paulo, the controlled wage gap is much smaller than the corresponding gross wage gap. This fact indicates that differences in the composition of the labor force are a major explanatory factor of the wage gap between the public and private sectors. Overall these differences in the composition of the labor force are responsible for the average log-wage in the public sector being from 0.5 to 
0.8 higher than in the private sector. Hence, sectoral differences in the composition of the labor force are responsible for a greater fraction of the gross public-private wage gap than is the actual wage advantage of the public sector. As a consequence, overall measures for the wage gap that do not control for differences in the characteristics of the labor force are bound to severely overestimate the actual wage advantage of workers in the public sector.

In sum, differences in the sectoral composition of the labor force are a major explanation for the wage gap between the public and private sector. One of the consequences is that once the differences in composition have been eliminated, the rather high wage gap between the two sectors, becomes rather small, with the Federal District being a noticeable exception: there the logwage gap declines from 1.18 to 0.50 , indicating a large decline but still a very large wage gap among workers with identical observed characteristics. This important result is illustrated in figures $3 \mathrm{a}$ and $3 \mathrm{~b}$, which present, for each region, the overall log-wage gap, the component explained by sectoral differences in composition of the labor force, and the component due to the differential payment of workers with identical observed characteristics. These figures reveal that in all cases the component due to the differential payment of workers with identical observed characteristics is much smaller than the correspondent overall log-wage gap.

\section{The contribution of specific characteristics}

While table 7 reveals that sectoral differences in the composition of the labor force are a major factor in explaining the wage gap between the public and private sectors, table 8 permits to identify the contribution of each characteristic. This table reveals that the higher educational level of the labor force in the public sector represents around $70 \%$ of the contribution of all characteristics to the wage gap. The remaining $30 \%$ are explained by the fact that public employees tend to be older and have longer tenure, with each of these two factors being responsible for 10 to $20 \%$ of the differential. The impact of the differences in the composition by gender and race is very small. Indeed, differences in race and gender composition between the private and public sectors are very small. Gender differences, in addition of being small have a negative impact, since women have lower wages and are overrepresented in the public sector. 


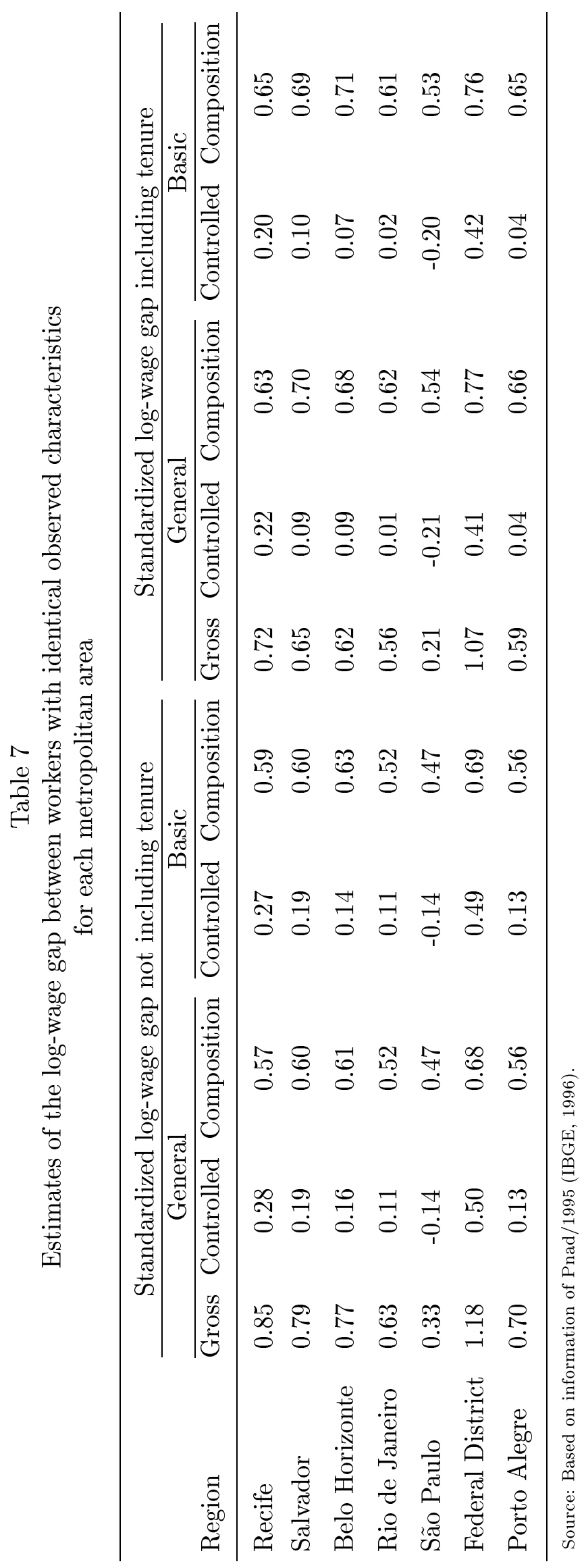


Figure $3 \mathrm{a}$

The overall log-wage gap between the public and private sectors and its components (without tenure)

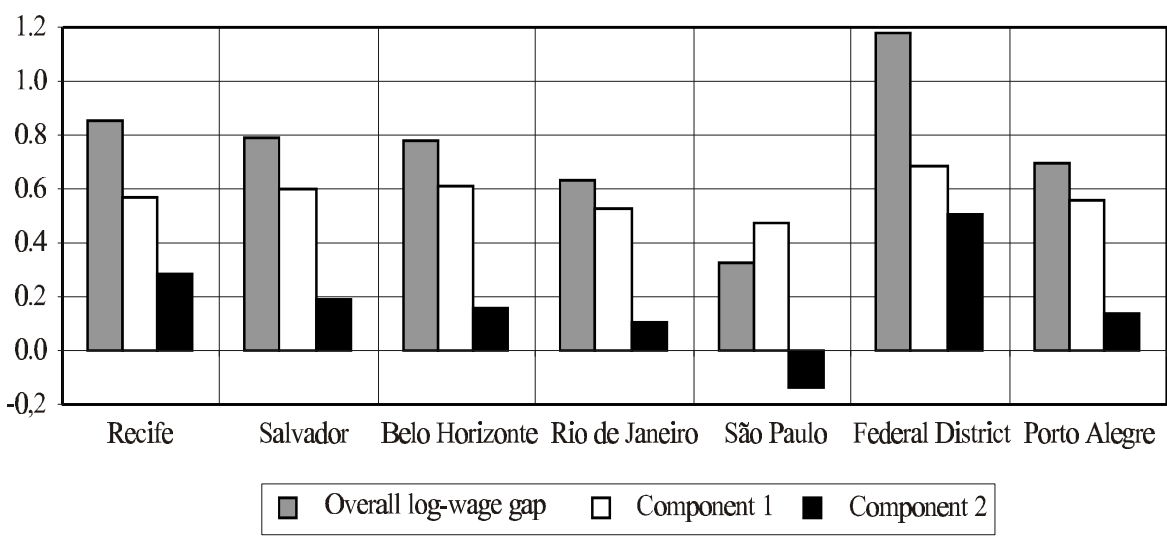

Source: Based on information of Pnad/1995 (IBGE, 1996).

Notes: Component 1 - explained by sectoral differences in composition of the labor force; component 2 - due to differential payment of workers with identical observed characteristics.

Figure $3 b$

The overall log-wage gap between the public and private sectors and its components (with tenure)

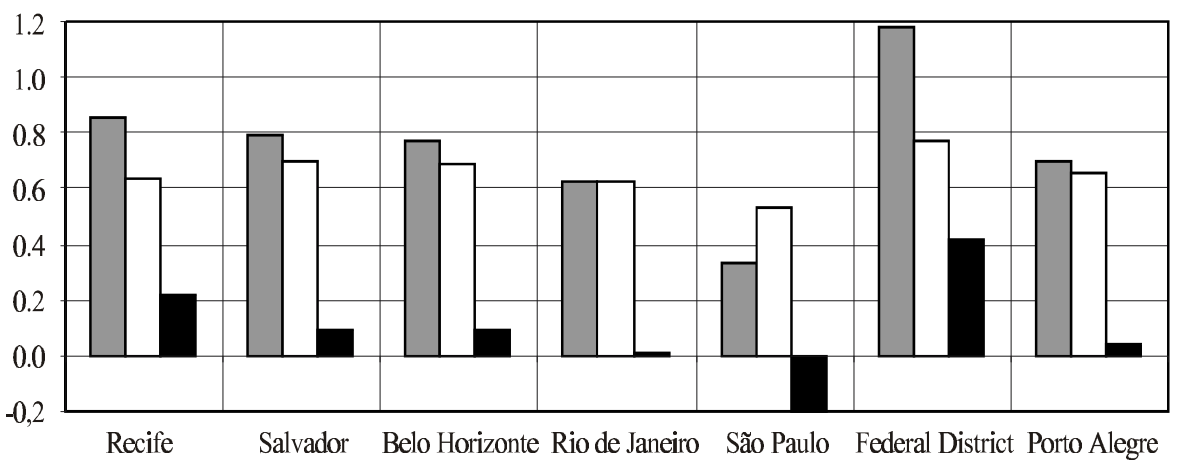

$\square$ Overall log-wage gap $\square$ Component $1 \quad \square$ Component 2

Source: Based on information of Pnad/1995 (IBGE, 1996).

Notes: Component 1 - explained by sectoral differences in composition of the labor force; component 2 - due to differential payment of workers with identical observed characteristics. 
Table 8

Contribution of specific characteristics for the controlled wage gap

\begin{tabular}{|c|c|c|c|c|}
\hline \multirow{2}{*}{ Region } & \multicolumn{2}{|c|}{ Level } & \multicolumn{2}{|c|}{ Percent } \\
\hline & General model & Basic model & General model & Basic model \\
\hline \multicolumn{5}{|l|}{ Recife } \\
\hline gender & -0.03 & -0.03 & -4.0 & -3.9 \\
\hline race & 0.01 & 0.01 & 1.4 & 1.5 \\
\hline education & 0.50 & 0.51 & 79.3 & 78.9 \\
\hline age & 0.07 & 0.07 & 11.3 & 11.4 \\
\hline tenure & 0.08 & 0.08 & 12.0 & 12.1 \\
\hline total & 0.63 & 0.65 & 100.0 & 100.0 \\
\hline \multicolumn{5}{|l|}{ Salvador } \\
\hline gender & -0.04 & -0.04 & -5.9 & -6.0 \\
\hline race & 0.04 & 0.04 & 5.4 & 5.6 \\
\hline education & 0.46 & 0.46 & 66.6 & 67.7 \\
\hline age & 0.11 & 0.11 & 15.5 & 15.6 \\
\hline tenure & 0.13 & 0.12 & 18.4 & 17.0 \\
\hline total & 0.70 & 0.69 & 100.0 & 100.0 \\
\hline \multicolumn{5}{|c|}{ Belo Horizonte } \\
\hline gender & -0.05 & -0.05 & -8.0 & -7.4 \\
\hline race & 0.03 & 0.03 & 4.8 & 4.5 \\
\hline education & 0.50 & 0.51 & 73.3 & 72.9 \\
\hline age & 0.11 & 0.11 & 16.2 & 15.6 \\
\hline tenure & 0.09 & 0.10 & 13.7 & 14.3 \\
\hline total & 0.68 & 0.71 & 100.0 & 100.0 \\
\hline \multicolumn{5}{|c|}{ Rio de Janeiro } \\
\hline gender & -0.01 & -0.01 & -0.9 & -1.0 \\
\hline race & 0.01 & 0.01 & 1.7 & 1.7 \\
\hline education & 0.44 & 0.43 & 70.2 & 71.0 \\
\hline age & 0.06 & 0.06 & 9.6 & 9.7 \\
\hline tenure & 0.12 & 0.11 & 19.4 & 18.6 \\
\hline total & 0.62 & 0.61 & 100.0 & 100.0 \\
\hline \multicolumn{5}{|l|}{ São Paulo } \\
\hline gender & -0.05 & -0.05 & -9.5 & -9.8 \\
\hline race & 0.00 & 0.00 & 0.9 & 0.9 \\
\hline education & 0.38 & 0.38 & 71.4 & 71.5 \\
\hline age & 0.11 & 0.11 & 20.4 & 20.3 \\
\hline tenure & 0.09 & 0.09 & 16.8 & 17.0 \\
\hline total & 0.54 & 0.53 & 100.0 & 100.0 \\
\hline \multicolumn{5}{|c|}{ Federal District } \\
\hline gender & 0.00 & 0.00 & 0.2 & 0.2 \\
\hline race & 0.02 & 0.02 & 2.3 & 2.3 \\
\hline education & 0.54 & 0.53 & 69.7 & 69.9 \\
\hline age & 0.10 & 0.11 & 13.5 & 14.8 \\
\hline tenure & 0.11 & 0.10 & 14.3 & 12.8 \\
\hline total & 0.77 & 0.76 & 100.0 & 100.0 \\
\hline \multicolumn{5}{|l|}{ Porto Alegre } \\
\hline gender & -0.03 & -0.03 & -4.1 & -4.1 \\
\hline race & 0.00 & 0.00 & 0.0 & 0.0 \\
\hline education & 0.51 & 0.50 & 76.9 & 77.0 \\
\hline age & 0.06 & 0.06 & 9.0 & 9.3 \\
\hline tenure & 0.12 & 0.12 & 18.1 & 17.7 \\
\hline total & 0.66 & 0.65 & 100.0 & 100.0 \\
\hline
\end{tabular}

Source: Based on information of Pnad/1995 (IBGE, 1996). 


\section{Regional comparisons}

Figures $4 \mathrm{a}$ and $4 \mathrm{~b}$ present our estimates for the controlled wage gap by metropolitan area. These figures indicate the existence of a very large regional variation in the controlled log-wage gap between the public and private sectors. The interpretation of these regional variations requires, however, considerable caution. For instance, the fact that in São Paulo equally productive workers receive lower wages in the public sector than in the private sector while in the Federal District the opposite is true does not necessarily implies that jobs in the public sector in São Paulo are particularly bad or that jobs in the public sector in the Federal District are particularly good. In fact, since all comparisons are relative to the private sectors of each specific region, the difference between São Paulo and the Federal District may indicate either that jobs in the public sector in the latter are better, or that jobs in the private sector in the former are better, or that both are true.

To investigate to what extent these regional differences in the controlled log-wage gap between the public and private sectors are due to regional differences in the quality of private jobs or due to regional differences in the quality of public jobs, we used our estimated regressions. Based on these regressions, we computed what would be the average wage of the labor force in the public sector of São Paulo if employed in the public and private sectors of each metropolitan area in the study. The results of these counter-factuals are presented in table 9 . By standardizing the composition of the labor force they permit a direct comparison of the quality of public and of private jobs in all metropolitan areas. This table reveals that the best segment of the labor market in these seven metropolitan areas is the public sector in the Federal District followed by the private sector in São Paulo. Hence, the controlled gap is much smaller in São Paulo than in the Federal District due two factors: a better public sector in the Federal District and a better private sector in São Paulo. The better public sector in the Federal District contributes to make the log-wage gap in this region 0.43 greater than in São Paulo, whereas the better private sector in São Paulo contributes to make this log-wage gap 0.25 greater. As a result, the log-wage gap is 0.68 greater in the Federal District, with the better conditions of the public sector in this region being more important than the better conditions of the private sector in São Paulo. Nevertheless, both factors operate in the same direction. 


\section{Figure 4a}

Controlled wage gap between the public and private sectors (without tenure)

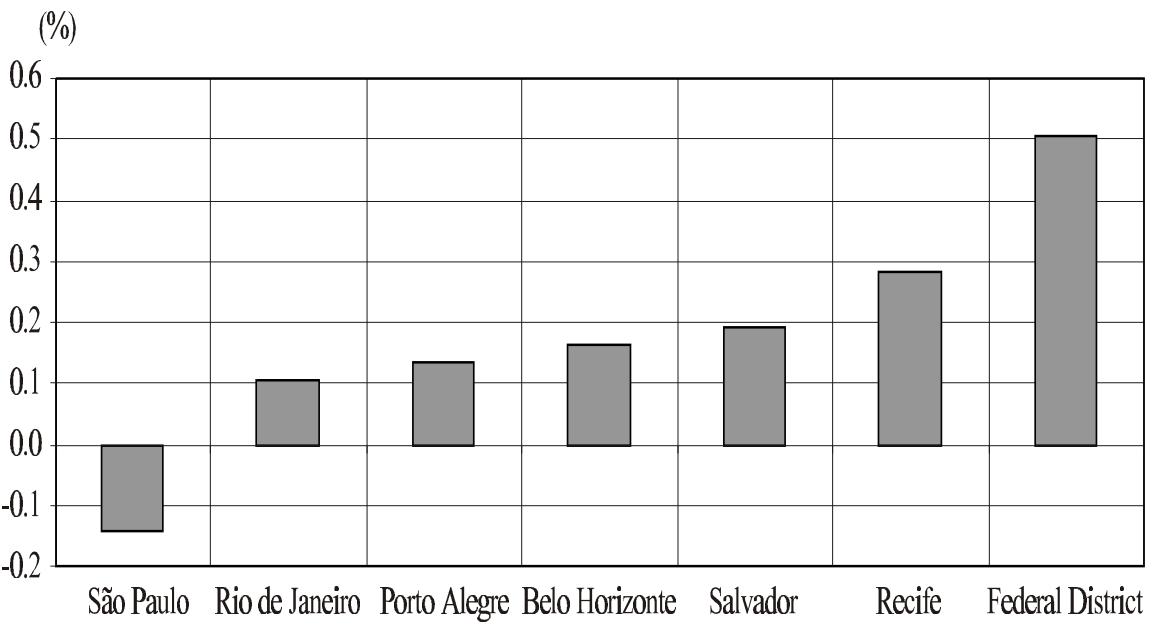

Fonte: Based on information of Pnad/1995 (BGE, 1996).

Figure $4 \mathrm{~b}$

Controlled wage gap between the public and private sectors (with tenure)

$$
(\%)
$$

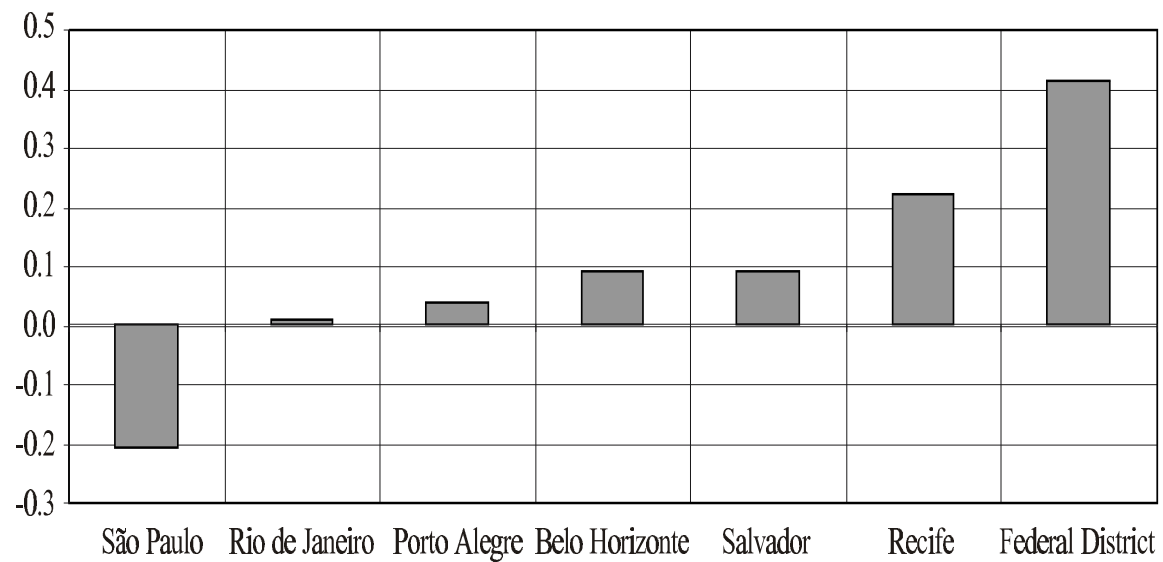

Fonte: Based on information of Pnad/1995 (IBGE, 1996). 
Table 9

Direct comparison of public and private jobs in metropolitan areas: the results of the counter-factuals

\begin{tabular}{|c|c|c|c|c|c|c|}
\hline \multirow{2}{*}{ Region } & \multicolumn{3}{|c|}{ Not including tenure } & \multicolumn{3}{|c|}{ Including tenure } \\
\hline & Public & Private & $\overline{\text { Wage gap }}$ & Public & Private & Wage gap \\
\hline Recife & -0.31 & -0.55 & 0.23 & -0.29 & -0.58 & 0.29 \\
\hline Salvador & -0.17 & -0.29 & 0.12 & -0.15 & -0.36 & 0.21 \\
\hline Belo Horizonte & -0.10 & -0.18 & 0.08 & -0.07 & -0.23 & 0.16 \\
\hline Rio de Janeiro & -0.17 & -0.19 & 0.02 & -0.15 & -0.25 & 0.10 \\
\hline São Paulo & 0.00 & 0.21 & -0.21 & 0.00 & 0.14 & -0.14 \\
\hline Federal District & 0.43 & -0.04 & 0.47 & 0.45 & -0.10 & 0.55 \\
\hline Porto Alegre & -0.04 & -0.11 & 0.06 & -0.02 & -0.18 & 0.15 \\
\hline
\end{tabular}

Source: Based on information of Pnad/1995 (IBGE, 1996).

Note: The counter-factual is: what would be the labor force in the public sector of São Paulo if employed in the public and private sectors of each metropolitan area.

This table reveals, however, that the difference between São Paulo and Recife has a completely distinct explanation. In this case, despite the controlled log-wage gap being considerably greater in Recife (0.23), the explanation is not the better quality of public jobs in Recife. On the contrary, the explanation is solely the better quality of private jobs in São Paulo. In fact, the quality of public jobs is greater in São Paulo and so cannot explain the lower wage advantage of workers in the public sector in this region. The greater log-wage gap in all other regions relative to São Paulo has the same explanation: a better private sector in São Paulo. To conclude, we emphasize that the negative controlled wage gap in São Paulo is not the result of an inferior public sector in this region, but of a superior private sector. In fact, only the Federal District has a better public sector than São Paulo.

\section{The Sensitivity to the Level of Geographical Aggregation}

To investigate the sensitivity to the level of geographical aggregation of the estimates for the wage advantage of the public sector (the controlled wage gap), we compare in this section estimates for metropolitan areas with estimates for the corresponding states. These estimates are presented in table 10 . The estimates for the metropolitan areas are those obtained in the previous section; the estimates for the corresponding states are obtained using an extended version of the basic model that includes an indicator for metropolitan area as an additional explanatory variable.

The results presented in table 10 reveal a clear difference between the Northeast and the South and Southeast regions. In the Northeast we obtain 
the expected result: the wage advantage of the public sector is greater for the metropolitan area than for the corresponding state as a whole, probably due to a greater share of municipal public sector for the state than for the metropolitan area. ${ }^{9}$ In the South and Southeast, the reverse is observed. The wage advantage of the public sector is greater for the state as a whole than for the corresponding metropolitan area. Overall, however, table 10 reveals that only in São Paulo and Pernambuco the wage advantage for the entire state and the metropolitan area really differ. In the other states the difference is smaller than 0.04 .

Table 10

Controlled wage-gap for states and metropolitan areas (1995)

(standardized wages)

\begin{tabular}{lcc}
\hline \multirow{2}{*}{ Region } & \multicolumn{2}{c}{ Controlled wage gap (basic model) } \\
\cline { 2 - 3 } & Not including tenure & Including tenure \\
\hline Pernambuco & 0.13 & 0.12 \\
$\quad$ State & 0.27 & 0.20 \\
$\quad$ Metropolitan area (Recife) & & \\
Bahia & 0.15 & 0.14 \\
$\quad$ State & 0.19 & 0.10 \\
$\quad$ Metropolitan area (Salvador) & & 0.13 \\
Minas Gerais & 0.14 & 0.07 \\
$\quad$ State & 0.14 & 0.05 \\
$\quad$ Metropolitan area (Belo Horizonte) & & 0.02 \\
Rio de Janeiro & 0.13 & -0.12 \\
$\quad$ State & 0.11 & -0.20 \\
$\quad$ Metropolitan area (Rio de Janeiro) & & \\
São Paulo & -0.07 & 0.42 \\
$\quad$ State & -0.14 & 0.12 \\
$\quad$ Metropolitan area (São Paulo) & & 0.04 \\
Federal District & 0.49 & \\
$\quad$ Metropolitan area & & \\
Rio Grande do Sul & & \\
$\quad$ State \\
$\quad$ Metropolitan area (Porto Alegre)
\end{tabular}

Source: Based on information of Pnad/1995 (IBGE, 1996).

\section{The Controlled Log-Wage Gap: a Disaggregated View}

In section 6 we investigated the degree of wage heterogeneity within the public sector. In that section we restricted the attention to the comparison of overall average wages, without paying attention to sectoral differences in the

\footnotetext{
${ }^{9}$ This result does not confirm for Bahia and its metropolitan area when we include tenure as an explanatory variable.
} 
composition of the labor force. To complement that analysis, in this section we estimate the log-wage gap between each segment of the public sector and the overall private sector, controlling for sectoral differences in the composition of the labor force.

Table 11 presents estimates for the internal composition of the public sector and for the controlled log-wage between each segment of the public sector and the private sector. This table reveals large differences among segments of the public sector with respect to their wage advantage. The wage advantage, measured by the controlled log-wage gap, is larger at federal level both among public servants and among employees in public enterprises. For these groups the average log-wage is 0.3 to 0.7 higher than for comparable workers in the private sector.

At the state level, the wage advantage is negative but very close to zero for public servants. For employees in public enterprises the wage advantage is positive and between 0.1 and 0.5 . At the municipal level, the wage advantage is negative or close to zero for both public servants and employees in public enterprises. Overall, the evidence corroborates the existence of large differences in the wage advantage of different segments of the public sector relative to the overall private sector. Moreover, these results indicate that even though the controlled gap is much smaller than the gross gap, the variations across segments of the public sector are the same: higher at the federal level and smaller at the municipal level.

\section{Conclusion}

The main objective of this study was to investigate the magnitude of the wage gap between the public and the private sectors in Brazil. In order to achieve this aim, we used data from the Pnad/1995, and calculated both the gross and the controlled public-private wage gap. The first measure compares average wages of the public and private sectors without taking into consideration potential differences in the (observable) characteristics of the labor force employed in the two sectors. The second measure estimates the publicprivate wage gap controlling for differences in gender, race, age, education, and tenure among workers of the two sectors. The main conclusions of the study are presented below. 


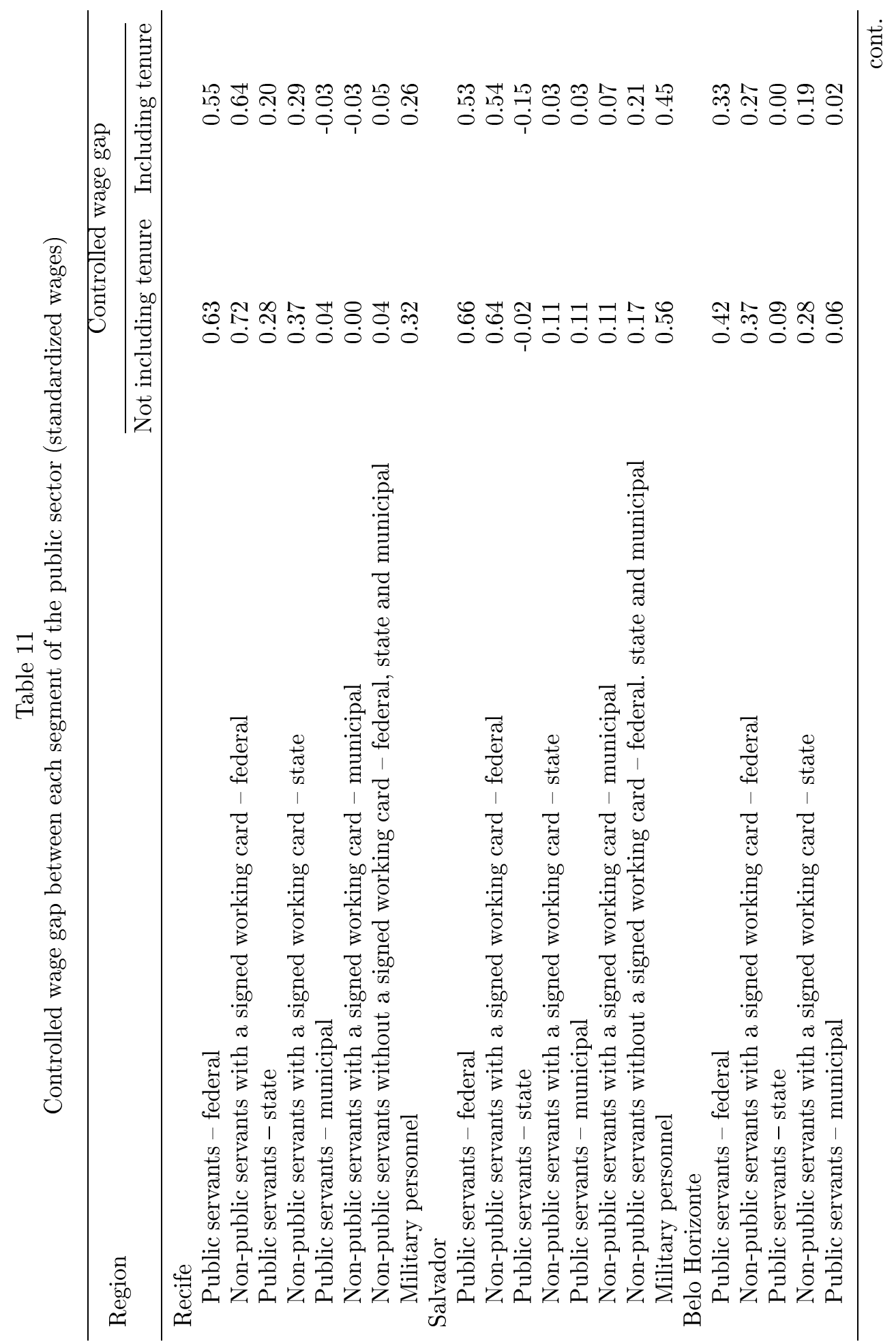




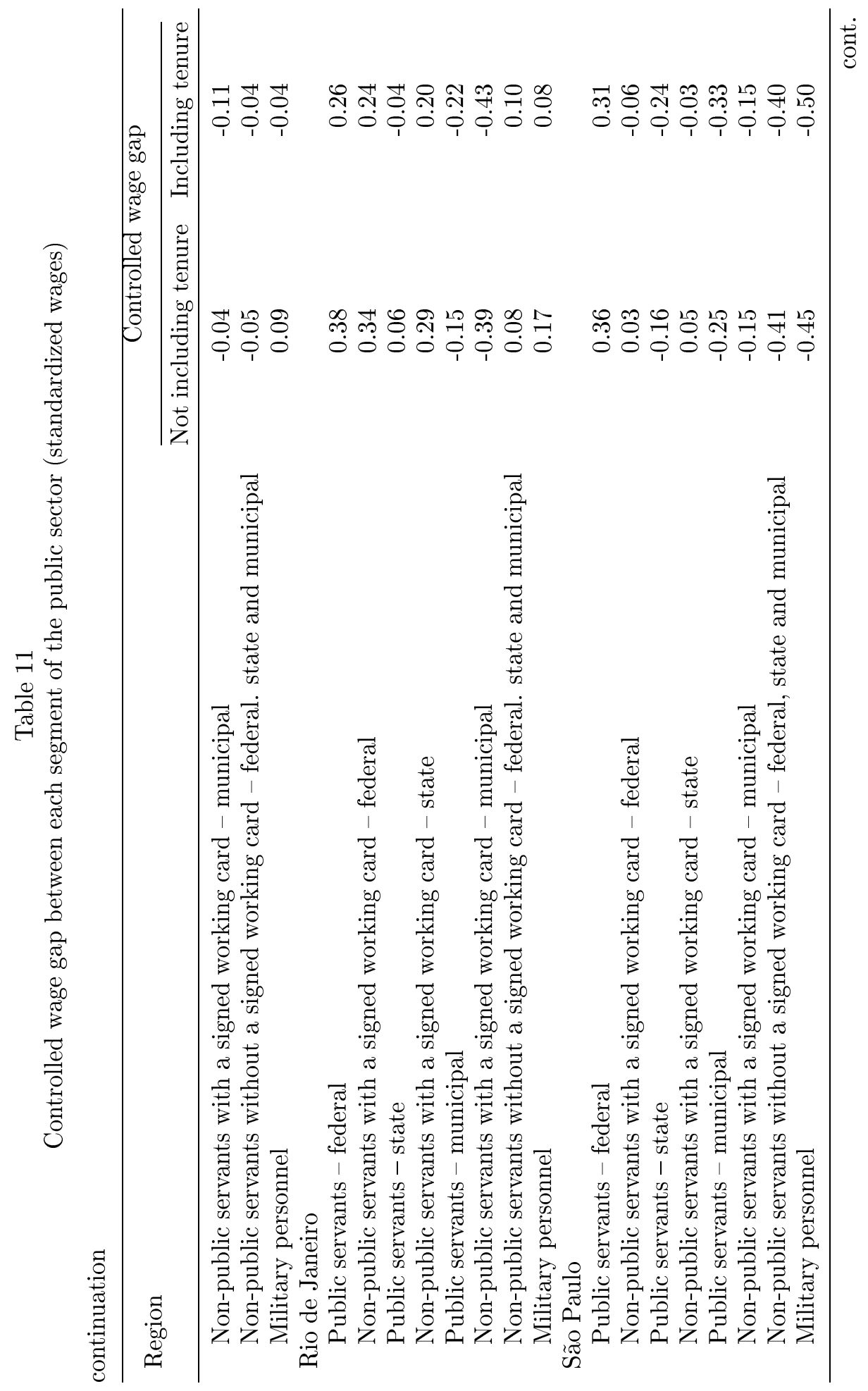




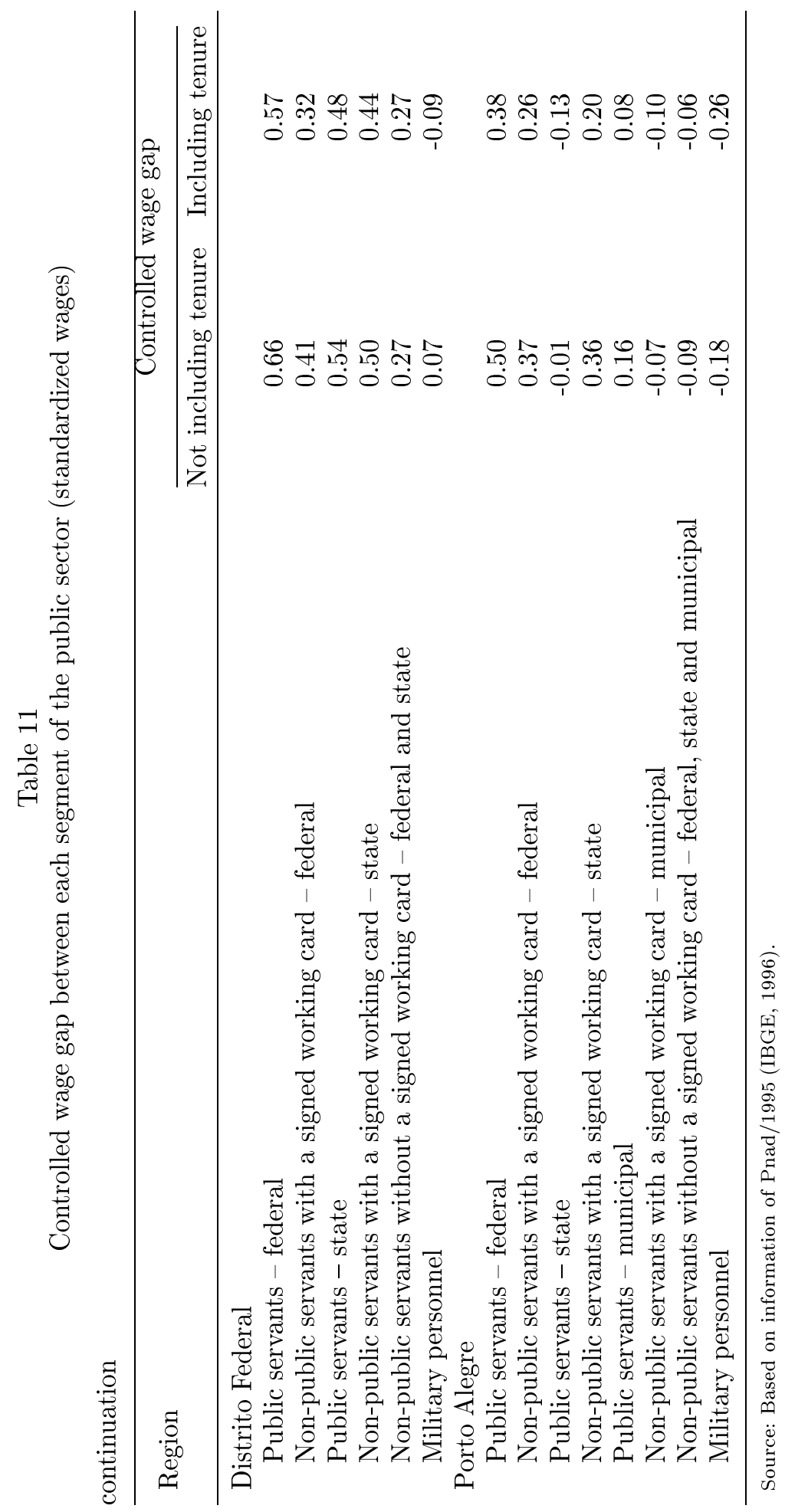


- The gross wage gap between the two sectors is relatively large. However, there is a great deal of heterogeneity within the public sector: the gross publicprivate wage gap of federal (including military personnel) and state level employees is high, while at the municipal level the public-private wage gap is negative.

- The overall wage gap varies across the states of the country, being particularly larger in the Federal District and the poorest states of the Northeast region.

- The controlled wage gap between the two sectors also appears to be relatively high and significant. However, they are lower than the gross wage gap indicating that there are important differences in the composition of the labor force between the two sectors. In other words, the gross wage gap tends to overestimate the actual advantage of the workers in the public sectors, since these workers tend to be on average better educated, older and have longer tenure than the workers in the private sector.

- Despite significantly high, the controlled public-private wage gap varies across the seven metropolitan areas investigated in this study, being even negative in São Paulo. This is not the result of an inferior public sector in São Paulo, but a superior private sector. In fact, only the Federal District has a better public sector than São Paulo.

\section{References}

Barros, Ricardo P. \& Ramos, Lauro. Employment structure in Brazil and its sensitivity to current economic policy. Rio de Janeiro, Ipea, 1991. (Texto para Discussão, 228.)

; Foguel, Miguel N. \& Mendonça, Rosane. The wage gap between

the public and private sectors in Brazil. Rio de Janeiro, Ipea, 1997. (Série Seminários, 13/97.)

Griliches, Zvi. Estimating the returns to schooling: some econometric problems. Econometrica, 45(1):1-21, 1977.

IBGE. Pesquisa Nacional por Amostra de Domicílios - Pnad: Síntese de indicadores 1995. Rio de Janeiro, IBGE, 1996.

Macedo, Roberto B. M. Os salários nas empresas estatais. São Paulo, Nobel, $1985 \mathrm{a}$. 
- Diferenciais de salários entre empresas privadas e estatais no Brasil. Revista Brasileira de Economia. Rio de Janeiro, FGV, 39(4):448-73, out./dez. 1985b.

Maia, Rosane \& Saldanha, Rosangela. Abrindo a caixa-preta... Estudo sobre a evolução do emprego na administração pública estadual e municipal. Brasília, Ministério do Trabalho, 1988. (Texto para Discussão, 12.)

Saldanha, Rosangela; Maia, Rosane \& Camargo, José Marangoni. Emprego e salário no setor público federal. Brasília, Ministério do Trabalho, 1988. (Texto para Discussão, 5.)

Theil, Henri. Economics and information theory. Chicago, Rand McNally, 1967.

\section{Appendix: Wage Gap Concepts}

In the empirical analysis of wage differentials it is common to use wages, log-wages, arithmetic means, and geometric means. In this appendix we briefly review the connection between these concepts and how they are used to obtain measures for the wage gap.

We begin reviewing the advantages and disadvantages of using differences in log-wages vis-à-vis absolute or relative differences in wages. To procede we need to introduce a notation. Let $w_{a}$ and $w_{b}$ be two average wages. They could be, for instance, the average wages in the public and private sectors, respectively. Using this notation, one can define the absolute wage difference $\left(G_{0}\right)$, two alternative versions for the relative wage difference $\left(G_{1 a}\right.$ e $\left.G_{1 b}\right)$, and the log-wage difference $\left(G_{2}\right)$ as follows:

$$
\begin{aligned}
& G_{0}=w_{a}-w_{b} \\
& G_{1 a}=\frac{w_{a}-w_{b}}{w_{a}} \\
& G_{1 b}=\frac{w_{a}-w_{b}}{w_{b}} \\
& G_{2}=\ln \left(w_{a}\right)-\ln \left(w_{b}\right)=\ln \left(w_{a} / w_{b}\right)
\end{aligned}
$$

The absolute wage difference, $G_{0}$, has one major disadvantage over the relative difference in wages, $G_{1 a}$ e $G_{1 b}$, and the difference in log-wages, $G_{2}$. The absolute difference is sensitive to the unit of measurement, while the other measures are not. 
By their turn, relative differences in wages, as $G_{1 a}$ e $G_{1 b}$, have a major disadvantage when compared to differences in log-wages, $G_{2}$. To define a relative wage difference it is necessary to elect a baseline wage as reference. As a consequence, this type of measure inherits the inconvenience of being sensitive to the choice of the baseline wage. Notice the difference between $G_{1 a}$ and $G_{1 b}$. Thus, for instance, if the average wages in the public and private sectors are 50 and 20 monetary units respectively, then the wage gap can be expressed in relative terms as $150 \%$ of the private sector average wage or $60 \%$ of the public sector average wage. The need to constantly refer to the chosen baseline wage makes the use of relative wage differences cumbersome in detailed analysis of wage differentials. One way to avoid this difficulty is to design measures of wage differentials that are insensitive to the choice of a baseline reference wage. The log-wage difference is such an alternative. In the example above, the log-wage difference between the public and private sectors will be 0.92 independently of the monetary units chosen and will not require a choice of a baseline wage for reference.

The log-wage difference, however, has as its major disadvantage the fact that it is more difficult to interpret. One way to facilitate its interpretation is to notice that, for small variations, the log-wage difference is an approximation for the relative change in the level of wages. For instance, if the wages are 50 and 51 the relative wage variations using 50 or 51 , as the baseline references are 0.0200 and 0.0196 , respectively. In this case the log-wage difference is 0.0198. In the general case, we have that if $w_{a}>w_{b}$ then

$$
\frac{w_{a}-w_{b}}{w_{a}} \geq \ln \left(\frac{w_{a}}{w_{b}}\right) \geq \frac{w_{a}-w_{b}}{w_{b}}
$$

or that

$$
G_{1 a} \geq G_{2} \geq G_{1 b}
$$

In sum, the log-wage difference has two useful properties: it eliminates the need to keep track of the wage used as reference and it gives an estimate for the wage gap that is between the two natural measures for the relative difference in wages. The major disadvantage of the log-wage difference is that it is difficult to interpret.

Up to now we are considering alternative methods for evaluating the relative difference between two average wages, where supposedly the average 
wage is simply the arithmetic mean of wages. The question of using the level of wages or their logs only appears after the average wage has been already obtained. However, in many circumstances the passage from wage levels to log-wages is conducted before taking averages. This is particularly ubiquitous to studies of wage differentials based on regression analysis, since they invariantly use log-wages as the dependent variable in regressions.

When logs are taken before the averages are obtained, comparisons between the logs of the averages are not any more comparisons between the logs of two arithmetic means. The comparison becomes one between the log of two geometric means. This is a consequence of the fact that the arithmetic mean of the logs is identical to the log of the geometric mean.

Thus, there is a third commonly used possibility for comparing the wages of two populations. This third possibility consists of computing the log difference between the geometric means, which is equivalent to computing the difference between the arithmetic mean of the logs. We refer to this measure as the gap in average log-wages and denote it by $G_{3}$. To make clear when we are using $G_{2}$ and when we are using $G_{3}$ we will always refer to $G_{2}$ as the gap in log-average-wages.

To clarify the differences between these alternative measures for the wage gap between two sectors, let $\left\{w_{a i}: i: 1, \cdots, n\right\}$ and $\left\{w_{b i}: i: 1, \cdots, m\right\}$ be the wages of workers in sectors $a$ and $b$, respectively. Using this notation, the three alternative measures for the relative wage gap introduced up to now can be expressed as:

$$
\begin{aligned}
& G_{1 a}=\frac{\frac{1}{n} \sum_{i=1}^{n} w_{a i}-\frac{1}{m} \sum_{i=1}^{m} w_{b i}}{\frac{1}{n} \sum_{i=1}^{m} w_{a i}} \\
& G_{1 b}=\frac{\frac{1}{n} \sum_{i=1}^{n} w_{a i}-\frac{1}{m} \sum_{i=1}^{m} w_{b i}}{\frac{1}{m} \sum_{i=1}^{m} w_{b i}} \\
& G_{2}=\ln \left(\frac{\frac{1}{n} \sum_{i=1}^{n} w_{a i}}{\frac{1}{m} \sum_{i=1}^{m} w_{b i}}\right)
\end{aligned}
$$


and

$$
G_{3}=\frac{1}{n} \sum_{i=1}^{n} \ln w_{a i}-\frac{1}{m} \sum_{i=1}^{m} \ln w_{b i}=\ln \left(\frac{\left(\prod_{i=1}^{n} w_{a i}\right)^{1 / n}}{\left(\prod_{i=1}^{m} w_{b i}\right)^{1 / m}}\right)
$$

Above we showed that $G_{2}$ is always between $G_{1 a}$ and $G_{1 b}$, but what is the connection between the level of $G_{3}$ and the level of the other measures? To some extent it is possible to relate the levels of $G_{2}$ and $G_{3}$. The connection between them is intrinsically related to the relative degree of wage inequality in the two sectors.

The simplest way to consider this question is to notice that the arithmetic mean is always greater than the geometric mean, except when all wages are the same. This fact led Theil (1967) to propose the log-difference between the arithmetic and geometric mean as a measure of wage inequality. Hence, if we define the wage inequality in these two populations by

$$
\begin{aligned}
& T_{a}=\ln \left(\frac{1}{n} \sum_{i=1}^{n} w_{a i}\right)-\ln \left(\left(\prod_{i=1}^{n} w_{a i}\right)^{1 / n}\right)=\ln \left(\frac{1}{n} \sum_{i=1}^{n} w_{a i}\right)-\frac{1}{n} \sum_{i=1}^{n} \ln w_{a i} \\
& T_{b}=\ln \left(\frac{1}{m} \sum_{i=1}^{m} w_{b i}\right)-\ln \left(\left(\prod_{i=1}^{m} w_{b i}\right)^{1 / m}\right)=\ln \left(\frac{1}{m} \sum_{i=1}^{m} w_{b i}\right)-\frac{1}{m} \sum_{i=1}^{m} \ln w_{b i}
\end{aligned}
$$

we obtain that

$$
G_{2}=G_{3}+\left(T_{a}-T_{b}\right)
$$

Therefore, we conclude that $G_{2}$ and $G_{3}$ will be the same if and only if the level of wage inequality, measured by the Theil index, is the same in both sectors. More generally, $G_{2}$ will be similar to $G_{3}$ if the levels of inequality in both sectors are similar. Whenever inequality is greater in sector $b$ than in sector $a$, we will tend to observe values for $G_{3}$ greater than the corresponding values for $G_{2}$. Unfortunately, this is precisely the situation when contrasting the public and private sectors. Wage inequality in the private sector tends to be greater, leading the gap in average log-wages $\left(G_{3}\right)$ to be greater than the gap in log-average-wages $\left(G_{2}\right)$. Table 3 (see the text) illustrates this question presenting estimates for the wage gap between the private and public sectors using all these measures. This table reveals that, as a consequence of the greater degree of wage inequality in the private sector, the wage gap between the public and private sectors tends to be much higher when measured by the gap in average log-wages $\left(G_{3}\right)$. 